\title{
Assistência de enfermagem em uma unidade de internação clínica durante a pandemia de COVID-19: relato de experiência
}

\author{
Nursing care in a clinical inpatient unit during the COVID-19 pandemic: experience report
}

Atención de enfermería en una unidad de internación clínica durante la pandemia de COVID-19: informe de experiencia

Rozemy Magda Vieira Gonçalves ${ }^{1}$, Terezinha de Fátima Gorreis ${ }^{1}$, Nicole Hertzog Rodrigues ${ }^{2 *}$, Elisangela Souza'.

\section{RESUMO}

Objetivo: Descrever as experiências vivenciadas por enfermeiras assistenciais nos casos suspeitos ou confirmados de COVID-19 em uma unidade de internação clínica. Relato da experiência: Relato de experiência de enfermeiras assistenciais de um hospital universitário de grande porte localizado em Porto Alegre, relacionado às medidas adotadas contra disseminação microbiológica do novo Coronavírus e manutenção das atividades em meio à pandemia em uma unidade de internação clínica. Frente à iminência da pandemia de COVID-19 foram implantadas medidas de distanciamento, incremento a higiene de superfícies e de mãos, redução de fluxo de pessoas, uso consciente e correto do equipamento de proteção individual, realização de atividades de educação em saúde e treinamentos sobre a correta paramentação e desparamentação. Além destas adequações, foram instituídos protocolos institucionais e realizados ajustes para a otimização de novas práticas de atendimento, visando minimizar a exposição de pacientes, familiares e profissionais frente ao vírus circulante. Considerações finais: Os ajustes nas práticas organizacionais e operacionais em uma unidade de internação clínica buscam assegurar um atendimento de excelência, buscando a redução na incidência de contaminação pelo COVID-19 no local.

Palavras-chave: Infecções por coronavírus, Pandemias, Cuidados de enfermagem.

\begin{abstract}
Objective: To describe the experiences of clinical nurses in suspected or confirmed cases of COVID-19 in a clinical inpatient unit. Experience report: Experience report of clinical nurses at a large university hospital located in Porto Alegre, related to measures taken against microbiological dissemination of the new Coronavirus and maintenance of activities amidst the pandemic in a clinical inpatient unit. Facing the imminence of the COVID-19 pandemic, measures were implemented to distance, increase surface and hand hygiene, reduce the flow of people, consciously and correctly use personal protective equipment, carry out health education activities and training on the correct dress and undress. In addition to these adjustments, institutional protocols were instituted and adjustments were made to optimize new care practices, aiming to minimize the exposure of patients, families and professionals to the circulating virus. Final considerations: The adjustments in organizational and operational practices in a clinical inpatient unit seek to ensure excellent service, seeking to reduce the incidence of contamination by COVID-19 at the location.
\end{abstract}

Key words: Coronavirus infections, Pandemics, Nursing care.

\footnotetext{
1 Hospital de Clínicas de Porto Alegre (HCPA), Porto Alegre - RS.

2 Universidade Federal de Ciências da Saúde de Porto Alegre (UFCSPA), Porto Alegre - RS.

*E-mail: nicolehertzogrodrigues@gmail.com
}

SUBMETIDO EM: 6/2021

PUBLICADO EM: 7/2021 


\section{RESUMEN}

Objetivo: Describir las experiencias de enfermeras clínicas en casos sospechosos o confirmados de COVID19 en una unidad de hospitalización clínica. Informe de experiencia: Informe de experiencia de enfermeras clínicas de un gran hospital universitario ubicado en Porto Alegre, relacionado con las medidas tomadas contra la diseminación microbiológica del nuevo Coronavirus y el mantenimiento de actividades en medio de la pandemia en una unidad de hospitalización clínica. Ante la inminencia de la pandemia COVID-19, se implementaron medidas para distanciar, incrementar la higiene de superficies y manos, disminuir el flujo de personas, utilizar consciente y correctamente equipos de protección personal, realizar actividades de educación en salud y capacitaciones sobre la correcta vestimenta y desvestirse. Además de estos ajustes, se instituyeron protocolos institucionales y se realizaron ajustes para optimizar nuevas prácticas de atención, con el objetivo de minimizar la exposición de pacientes, familiares y profesionales al virus circulante. Consideraciones finales: Los ajustes en las prácticas organizacionales y operativas en una unidad de internación clínica buscan asegurar un excelente servicio, buscando reducir la incidencia de contaminación por COVID-19 en el lugar.

Palabras clave: Infecciones por coronavirus, Pandemias, Atención de enfermería.

\section{INTRODUÇÃO}

A epidemia causada pelo novo Coronavírus (SARS-CoV-2) tornou-se um problema de saúde pública mundial, propagando-se de forma rápida e tornando-se uma pandemia. Medidas que visem à contenção do vírus são analisadas em todos os países afetados pela infecção, com o intuito de assegurar barreiras que impeçam o aumento do quantitativo de casos de infecção (NASCIMENTO CS, et al., 2020).

Os serviços de saúde enfrentam um novo cenário de ações em segurança em saúde voltada aos profissionais, pacientes, familiares e sociedade, tornando-se um desafio a prevenção da propagação do vírus causador da doença conhecida como COVID-19 (WHO, 2020).

O quadro da doença possui variação quanto a sua apresentação, podendo ser assintomático ou até mesmo uma síndrome respiratória grave, que pode vir a se tornar letal dependendo da situação (MOREIRA RS, 2020). A contaminação pelo vírus ocorre através de gotículas ou secreção de uma pessoa contaminada, esse contato pode ser oriundo de um espirro, tosse ou toque em local contaminado (BRASIL, 2020).

O diagnóstico de COVID-19 é realizado por meio de avaliação da condição clínica e do exame físico. O diagnóstico laboratorial para identificação direta do vírus SARS-CoV-2 é realizado por meio das técnicas de RT-PCR, tido como referência para a confirmação do diagnóstico (BRASIL, 2020).

Os serviços de saúde muitas vezes deparam-se com a rápida propagação e contaminação do vírus entre os profissionais atuantes na assistência que lidam com casos de pacientes suspeitos ou confirmados em seu local de trabalho (ARONS MM, et al., 2020). As principais barreiras para conter a disseminação do vírus consistem em basicamente de medidas de isolamento social, utilização de máscaras, Equipamentos de Proteção Individual (EPI) e coletiva e cuidados com a higienização (NASCIMENTO CS, et al., 2020).

No início da pandemia, uma das principais preocupações dos profissionais de saúde estava relacionada à como deve ser realizado o atendimento ao paciente que apresenta suspeita ou confirmação da doença. Este primeiro contato com o paciente ainda é permeado por dúvidas e inseguranças, principalmente devido às mudanças recorrentes nos fluxos de atendimento e o medo com a contaminação (RODRIGUES NH e SILVA LGA, 2020).

Torna-se um grande desafio para as instituições de saúde as repercuções vivenciadas diante deste vírus de alta propagação na população, e que, causa mudanças drásticas nas rotinas dos serviços de saúde, onde se têm maior número de internações hospitalares em decorrência dos agravos respiratórios. Procedimentos organizacionais com o objetivo de contribuir para a prevenção e a segurança do paciente e profissional devem ser previstos (GALLASCH CH, et al., 2020). 
Alterações na estrutura dos fluxos operacionais dos serviços são essenciais nessa conjuntura, tendo em mente a segurança e qualidade do serviço oferecido. Dessa forma, é de vital importância a educação em serviço e a oferta de treinamentos para os colaboradores para o uso correto das barreiras à exposição, bem como dos ajustes realizados na estrutura de fluxos operacionais de serviço e de protocolos institucionais (RODRIGUES NH e SILVA LGA, 2020).

O cenário dessa pandemia modifica-se a cada dia, exigindo revisão constante de estratégias utilizadas para o atendimento de pacientes em instituições hospitalares, tais como alterações em espaços físicos, fluxos de serviço e habilitação de recursos humanos. Assim, frente a esta pandemia, o objetivo deste estudo foi descrever as experiências vivenciadas por enfermeiras assistenciais nos casos suspeitos ou confirmados de COVID-19 em uma unidade de internação clínica de um hospital da região metropolitana de Porto Alegre.

\section{RELATO DE EXPERIÊNCIA}

O relato delimita-se na experiência vivenciada no período de março de 2020 a março de 2021 e baseia-se na experiência de enfermeiras frente ao gerenciamento do setor, de pessoal e de materiais frente à pandemia de COVID- 19. O lócus de ação deste relato foi extraído do cotidiano profissional das autoras deste artigo por meio da experiência profissional adquirida durante a pandemia de Coronavírus.

O cenário deste relato trata-se de um hospital de grande porte que admite inúmeras especialidades pelo Sistema Único de Saúde (SUS), principalmente atendimentos direcionados ao tratamento de pacientes cirúrgicos, clínicos, oncológicos, com cardiopatias severas, doenças reumatológicas, gastroenterológicas, neurológicas, transplantados e com pneumopatias.

Em sua maior parte, os pacientes enquadram-se no grupo de pessoas suscetíveis a COVID-19 devido à baixa imunidade conferida pelas doenças e inúmeras comorbidades. A instituição hospitalar rapidamente se transformou em referência para o tratamento de pacientes com COVID-19. Planos de contingência foram elaborados, unidades para internações reorganizadas juntamente com a contratação e remanejo de pessoal para 0 adequado atendimento a esses pacientes.

Frente à iminência da pandemia de COVID-19, as medidas implantadas foram principalmente: medidas de distanciamento entre pacientes, manutenção de cortinas entre os leitos fechadas (evitando propagação de gotículas), distanciamento entre a equipe durante passagem de plantão e intervalos, incremento a higiene de superfícies e de mãos, redução de fluxo de pessoas, promoção de treinamentos relacionados à temática COVID-19, uso de EPI, medidas educativas para o uso consciente de materiais, dada escassez do momento e medidas de prevenção para pacientes e familiares.

Além destas adequações, foram implementados protocolos institucionais e realizados ajustes para a otimização de novas práticas de atendimento, visando minimizar a exposição dos pacientes, familiares e profissionais frente ao vírus. A exemplo disso, houve aumento do número de funcionários mediante a contratação emergencial, bloqueio de visitas e suspensão de rounds de discussões presenciais que passaram a ser realizados via aplicativos de mensagens instantâneas.

Realizaram-se ainda encontros para definição e organização de fluxos e protocolos com a atuação direta de enfermeiros nos processos relacionados à assistência direta. Foram implementados ajustes no processo de enfermagem realizado no hospital com a inclusão de diagnósticos de enfermagem e cuidados específicos com base nos novos fluxos e rotinas. Houve uma reestruturação da área física, tendo em vista o risco de transmissão e diversas sequelas decorrentes da doença. Realizou-se treinamento de profissionais com adequação ao dimensionamento apresentado nas áreas conforme o grau de complexidade de serviço, buscando qualificar profissionais nos cuidados críticos. Aplicou-se treinamentos para o desenvolvimento de conhecimentos e habilidades previamente aos primeiros casos confirmados, que foram mantidos ou ajustados mediante a revisão sistemática.

Ademais, observou-se preocupação dos enfermeiros com relação à saúde mental dos profissionais atuantes nesta unidade. Percebeu-se que a relação com a sobrecarga de saúde mental relacionado com a 
maior carga de trabalho após múltiplos afastamentos de colegas que apresentaram testes positivo para COVID-19, associado ao aumento da ansiedade dos pacientes internados devido a falta de familiares e medo da internação e de contágio do vírus, foi citado como fonte de desordem mental ou psíquica entre a classe de profissionais de enfermagem no decorrer do período estudado.

Visitas aos doentes internados foram suspensas, datas e horários fixados para entrega de pertences e em casos de extrema necessidade (idosos, paciente com risco para quedas ou totalmente dependentes), foi autorizada a permanência de acompanhante, obedecendo aos cuidados estipulados no contexto hospitalar de uma pandemia. Pacientes com diagnóstico de COVID-19 passaram a ficar isolados, passou-se a ser utilizada a chamada de vídeo via aplicativo de mensagens como recurso para conversa com familiares e notícias via telefone.

Pacientes que apresentaram diagnóstico positivo permaneceram isolados até a transferência para a unidade especializada em tratamento para COVID-19, o transporte do paciente foi realizado com a equipe de enfermagem devidamente paramentada e o paciente usando máscara de proteção adequada ou com as vias aéreas mantidas em sistema fechado de ventilação mecânica de acordo com as condições clínicas.

No caso de estarem em quarto coletivo e testarem positivo para COVID-19 durante a internação, os demais pacientes do quarto também foram testados e caso o PCR positivo, estes também foram transferidos e o quarto passou por uma limpeza terminal (verticais ou horizontais e desinfecção do mobiliário). Enquanto os demais pacientes aguardavam o resultado, o leito ao lado permanecia bloqueado.

As reformulações adotadas no atendimento a esses pacientes basearam-se no estudo de materiais científicos atuais publicados, levou-se em consideração principalmente as diretrizes do Ministério da Saúde (MS), da Organização Mundial da Saúde (OMS) e Secretaria Estadual de Saúde do estado do Rio Grande do Sul, tendo como objetivo a continuidade da assistência aos pacientes no decorrer da pandemia de COVID19. Mesmo com novas contratações em caráter emergencial, a sobrecarga de trabalho era inevitável e para atender as demandas de alguns setores, diferentes profissionais acabaram por sofrer um aumento em sua carga horária.

Para a confecção do artigo, foi realizada a descrição e discussão das ações implementadas pela instituição aos profissionais, pacientes e acompanhantes. Para a realização da discussão foram realizadas observações e diálogos entre as autoras do relato no ambiente interno do serviço e houve incorporação de embasamento técnico científico.

\section{DISCUSSÃO}

A equipe de enfermagem composta por enfermeiro, técnico de enfermagem e auxiliar de enfermagem são profissionais primordiais no atendimento na linha de frente aos pacientes com casos suspeitos ou confirmados de COVID-19. Atuando na assistência e disseminação do conhecimento para a população institucional ou geral por meio de educação em saúde, através do diálogo com a comunidade acerca das questões da prevenção da contaminação e infecção pela COVID-19, buscando dessa forma retardar o pico epidemiológico da doença (OPAS, 2020).

Esta realidade vivida na pandemia foi, e está sendo, arduamente batalhada pela enfermagem que tanto se orgulha de sua dedicação em prol da saúde do outro. Mesmo que em muitas situações tragam desesperança e medo a enfermagem se faz presente educando, apoiando e inovando para um cuidado humanizado e de excelência. Para o manejo e cuidados aos pacientes com casos suspeitos ou confirmados de COVID-19, protocolos e rotinas foram criados da noite para o dia na instituição (SILVA SGO, et al., 2020).

Assim como nesta instituição hospitalar, diversos serviços de saúde tiveram que adequar suas rotinas. Dada a magnitude da pandemia, todas as adequações e ações incorporadas na estrutura e nos fluxogramas de atendimento buscam atender as recomendações do MS e Secretaria de Saúde do Estado do Rio Grande do Sul, para buscar diminuir a exposição do paciente ao vírus durante o atendimento (SILVA SGO, et al., 2020). 
Dentro deste panorama mundial, é vital que os órgãos responsáveis estabeleçam fluxos padronizados para a assistência destes pacientes. Sendo assim, com o objetivo de realizar uma assistência ordenada e organizada nos serviços de saúde, o MS propôs a incorporação de fluxos de atendimentos divididos em dois momentos: o hospitalar que ocorre internamente nas instituições hospitalares e o não hospitalar, que vêm ocorrendo em containers ou tendas. (BRASIL, 2020).

O MS orienta ainda a manutenção de um fluxo de atendimento ágil, de forma que ocorra uma classificação por nível de prioridade e que disponha de uma equipe composta por um médico, um enfermeiro e um técnico de enfermagem para a assistência, bem como de um local exclusivo para atendimento (BRASIL, 2020).

É primordial garantir a segurança e proteção dos profissionais de saúde contra o vírus por meio da utilização e capacitação para uso correto do EPI, com o intuito de assegurar que estes não atuem como vetores de transmissão, além de evitar seu adoecimento para que também se possa manter e preservar o atendimento à população necessitada (WANG J, et al., 2020). Entretanto, é preciso lembrar que a existência de falhas na proteção desses trabalhadores têm sido uma realidade observada em diversos países (YONG L, et al., 2020).

As adequações que os profissionais da saúde acabaram por vivenciar em seu âmbito de atuação profissional podem ser um dos principais desafios diante desta pandemia. Como ações que têm gerado grandes preocupações para estes profissionais assistenciais temos: o atendimento ao paciente suspeito ou confirmado, carga horária de trabalho, paramentação, uso correto dos EPI e aumento da complexidade assistencial (RODRIGUES NH e SILVA LGA, 2020).

Não podemos esquecer que nesse contexto o estresse emocional é adicionado, tanto para a equipe de enfermagem, quanto para os pacientes. Trata-se de uma doença que amedronta a todos, onde muitas dúvidas ainda pairam sobre as vacinas e quando todos realmente terão este alcance. Mais uma vez o enfermeiro responsável tem de estar atento, procurando ajudar sua equipe no gerenciamento do processo de estresse e esgotamento mental pela situação vivenciada. O medo e apreensão é contínuo e relaciona-se principalmente ao risco de expor-se ao vírus e a preocupação de contágio de suas famílias (RODRIGUES NH e SILVA LGA, 2020).

Um sentimento de estresse por ser originado por fatores internos ou externos e pode gerar sentimentos como medo, ansiedade, apreensão ou ameaça. Esse sentimento não carece ser compreendido como um estado estático, visto que trata-se de um processo dinâmico e complexo estando relacionado negativamente à exaustão emocional e positivamente à satisfação no trabalho (CHOU HY, et al., 2011).

Em todo o mundo, os diferentes profissionais atuantes na área da saúde pagaram um preço alto no combate a este vírus. Todo profissional adoecido significa um risco aumentado para a população, visto que além de ser uma fonte de doenças infecciosas também acaba por afastar-se do trabalho e desfalcar sua equipe, gerando ainda mais, sobrecarga de trabalho dos demais profissionais envolvidos. O impacto real da pandemia relacionada à saúde dos profissionais ainda é desconhecido (JUNIOR AMF, et al., 2021). Entretanto, ainda assim, é possível constatar o grande empenho dos profissionais para a realização de um trabalho eficaz diante de um evento desconhecido na saúde (SOUZA TM e LOPES GS, 2021).

As práticas organizacionais e operacionais em uma unidade de internação clínica buscaram assegurar um atendimento de excelência, otimizando a redução na incidência de contaminação pelo COVID-19 a equipe e ao público circulante no local. A experiência para a assistência de enfermagem em uma unidade de internação clínica durante a pandemia vem sendo valiosa, pois possibilita o incremento de novos meios de se promover o atendimento, assim como possibilita a continuidade do tratamento aos pacientes, trabalhando na observação de sinais e sintomas de COVID-19 nessa população.

Quanto aos pacientes, rapidamente podem mudar seu quadro clínico e a enfermagem possui grande responsabilidade no reconhecimento para o suporte adequado no tempo competente. No atual cenário da COVID-19, compreende-se a complexidade que envolve os diversos processos de trabalho da enfermagem, em especial na prevenção e tratamento das pessoas acometidas, com reflexos no processo de adoecimento ou mesmo em mortes desses profissionais (CLEMENTINO FS, et al., 2020). 
A referida instituição hospitalar estuda manter esta configuração de atendimento mesmo no pós pandemia, realizando alterações que forem pertinentes. Com o surgimento de novos casos na presença de novas cepas deste vírus e consequente aumento da demanda de pacientes, a cada dia a enfermagem vem sendo solicitada e realocada ainda mais. Ajustes nas práticas organizacionais para um atendimento interprofissional organizado e seguro ao paciente em uma unidade de internação, tornam-se necessários frente a esta pandemia. Este relato almeja embasar outros serviços em relação a novas práticas de atendimento que não exponham o paciente e os profissionais ao contágio da COVID-19 e assim, buscar conter o avanço da pandemia.

\section{REFERÊNCIAS}

1. ARONS MM, et al. Presymptomatic SARS-CoV-2 infections and transmission in a skilled nursing facility. The new england journal of medicine, 2020; 382(22):2081- 90.

2. BRASIL. Manual do Ministério de Saúde: 2a Etapa Fluxogramas COVID-19 SAES Z. 2020. Disponível em: https://www.saude.ms.gov.br/wp-content/uploads/2020/03/2-Etapa-Fluxogramas-COVID-19-SAES-Z.pdf. Acesso em: 2 de junho de 2021.

3. BRASIL. Sobre a doença. In: Ministério da saúde. Governo federal. Disponível em: https://coronavirus.saude.gov.br/sobre-a-doenca. Acesso em: 26 mai. 2021.

4. CHOU HY, et al. Predicting nurses well-being from jobs demands and resources: a cross-sectional study of emotional labour. Journal of Nursing Management, 2011; 20(4):502-511.

5. CLEMENTINO FS, et al. Enfermagem na atenção às pessoas com COVID-19: desafios na atuação do sistema COFEN/CORENS. Texto e Contexto Enfermagem, 2020; 29: e20200251.

6. GALLASCH CH, et al. Prevention related to the occupational exposure of health professionals workers in the COVID19 scenario. Revista Enfermagem UERJ, 2020; 28:e49596.

7. JUNIOR AMF, et al. Sentimentos e vivências dos profissionais da enfermagem no combate ao coronavírus. Revista Eletrônica Acervo Enfermagem, 2021; 9(e6294): 1-6.

8. MOREIRA RS. COVID-19: unidades de terapia intensiva, ventiladores mecânico e perfis latentes de mortalidade associados à letalidade no Brasil. Cad. Saúde Pública, 2020; 36(5): 1678-4464.

9. NASCIMENTO CS, et al. Medidas de contenção do vírus Sars-CoV-2 em tempos pandêmicos: uma questão de saúde pública. Revista Eletrônica Acervo Enfermagem, 2020; 6(1): 1-8.

10. ORGANIZAÇÃO PAN-AMERICANA DE SAÚDE (OPAS). OMS define 2020 como o internacional dos profissionais e obstetrícia. Brasília: Distrito Federal. 2020. Disponível em: https://www.paho.org/pt/noticias/3-1-2020-oms-define2020-como-ano-internacional-dos-profissionais-enfermagem-e-obstetricia. Acesso em: 1 jun. 2021.

11. RODRIGUES NH, SILVA LGA. Gestão da pandemia coronavírus: relato de experiência profissional. Journal of Nursing and Health, 2020;10(n.esp.):e20104004.

12. SILVA SGO, et al. Centro de oncologia e infusão: desafios da equipe interprofissional frente à pandemia Coronavírus. Journal of Nursing and Health, 2020; 10(n.esp.):e20104022.

13. SOUZA TM, LOPES GS. Assistência de enfermagem em terapia intensiva ao paciente com Covid 19: um relato de experiência. Revista Eletrônica Acervo Enfermagem, 2021; 9(e6118): 1-6.

14. WANG J, et al. Exploring the reasons for healthcare workers infected with novel coronavirus disease 2019 (COVID19) in China. Journal of Hospital Infection, 2020; 105: 100-101.

15. WORLD HEALTH ORGANIZATION (WHO). Rolling updates on coronavirus disease, 2020. Disponível em: https://www.who.int/emergencies/diseases/novel-coronavirus-2019/events-as-they-happen. Acesso em: 26 mai. 2021.

16. YONG L, et al. Critical care response to a hospital outbreak of the 2019-nCoV infection in Shenzhen, China. Critical Care. 2020; 24(56):1-3. 